\title{
Gangrenous meckel's diverticulum in a strangulated umbilical hernia in a 42 year-old woman: a case report
}

\author{
Ilker Sengul ${ }^{1 *}$, Demet Sengul ${ }^{2}$, Serhat Avcu ${ }^{3}$, Omer Parlak ${ }^{4}$
}

\begin{abstract}
Introduction: Meckel's diverticulum affects 1 - 3\% of general population and is known as the most common anomaly of gastrointestinal tract. However, its estimated lifetime complication rate is approximately $4 \%$. Intestinal obstruction is most common complication of Meckel's diverticulum in adult population.

Case presentation: In the present study, we reported a 42-year-old female patient with a gangrenous Meckel's diverticulum in a strangulated umbilical hernia sac treated by dissection of diverticulomesenteric bands and diverticulectomy. In 36 months follow-up, there was neither any complication nor recurrence of hernia.

Conclusion: This case represents a gangrenous Meckel's diverticulum in a strangulated umbilical hernia sac diagnosed in case of emergency. Although it is a very rare phenomenon, we should be vigilant for this entity especially in case of emergency.
\end{abstract}

\section{Introduction}

Firstly in 1700, Littre reported two patients with traction diverticula in an inguinal hernia sac that is known as Meckel's diverticulum today. Also in 1777, a similar case with a hernia including some amount of intestinal wall was falsely reported as same entity. Meckel described the small bowel diverticula now called with his own name in 1800 [1].

Meckel's diverticulum is reported to occur in 1-3\% of general population and autopsy series, and it is also known as the most common anomaly of gastrointestinal tract $[2,3]$. It is found in men more frequently $(63 \%)$ than women $[4,5]$ and $30 \%$ of patients have other anomalies [6]. Although its anatomic localization is not constant, it most often occurs in $100 \mathrm{~cm}$ ileal portion, proximal to ileocecal valve [7]. Also, length of this diverticulum changes from $0.5 \mathrm{~cm}$ to $85 \mathrm{~cm}$, but mean length is reported as $5 \mathrm{~cm} \mathrm{[8].}$

\section{Case presentation}

A 42-year-old female was admitted to our department in December 2006 with complaints of pain and a mass on

\footnotetext{
*Correspondence: dr.ilker52@mynet.com

'Department of General Surgery, Giresun University Faculty of Medicine, 28100 Giresun, Turkey
}

the umbilical region of her body. She had had a mass increasing in size during past 5 years on the umbilical area and a localized sharp manner pain that its intensity increased especially during past 2 weeks also.

On physical examination; distended abdomen and protruding and deformed umbilicus were detected. The skin of umbilical region was indurated, erythematoused and sensitive. Temperature of the skin on the mass was also increased. A soft, mobile mass of nearly $4 \times 3 \mathrm{~cm}$ in size on the umbilical region and a longitudinal fascial defect of approximately $3 \mathrm{~cm}$ in length including both the umbilicus and the adjacent part of linea alba were palpated. During the operation performed under exigent conditions, umbilical defect was exposed. The part of small intestine that was discoloured to grayish-black of $7 \mathrm{~cm}$ in size was determined as Meckel's diverticulum. The fibrous bands of diverticulum associated with intestinal mesentery were dissected and then diverticulectomy and end to end ileoileal anastomosis were performed. Lastly, herniorrhaphy was performed for the fascial defect.

Microscopic examinations revealed mucosal infarctions in some places of diverticulum, and diverticular structure was laid down with heterotopic small intestinal mucosa (Figure 1, and Figure 2). Neither complication 




Figure 1 Congestive vascular structures and massive hemorrhagic findings under the surface epithelium of small bowel (Haematoxylin \& Eosin, Original magnification $\times 40$ ).

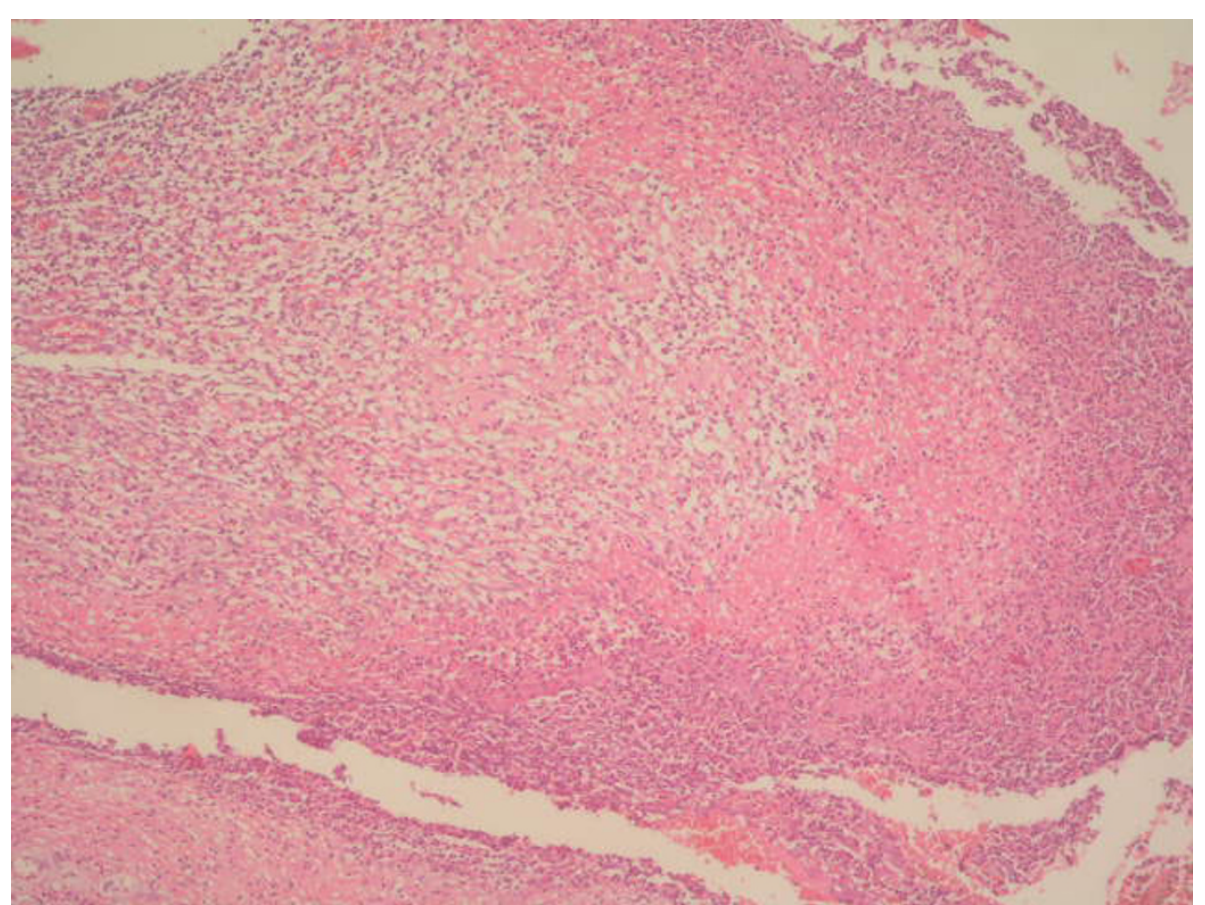

Figure 2 Massive ulceration on the surface epithelium of small bowel (Haematoxylin \& Eosin, Original magnification $\times 40$ ). 
nor recurrence of hernia was detected during 36 months follow-up.

\section{Discussion}

Incomplete obliteration of omphalomesenteric (vitelline) duct which must be obliterated during $8^{\text {th }}$ week of gestation under normal conditions, results mostly in Meckel's diverticulum. These are true diverticula, because they include all layers of small bowel wall. Microscopically nearly $60 \%$ of Meckel's diverticula contain heterotopic mucosa [7]. Perforation, vesicodiverticular fistula, bleeding, ulceration, intestinal obstruction, intussuseption, and tumors are denoted in complications of Meckel's diverticulum [9]. Most common tumor arising from Meckel's diverticulum is carcinoid tumors and its reported incidence is only $2 \%$ [10].

Although the lifetime complication rate of the disease is estimated nearly $4 \%$, more than half of patients in whom arising symptoms of complications of that are younger than 10 years old. In adults, most common complication of Meckel's diverticulum is intestinal obstruction; but in children, it is bleeding [7]. In our case, we detected a strangulated, gangrenous Meckel's diverticulum of $7 \mathrm{~cm}$ in size in a strangulated umbilical hernia sac and we performed dissection of diverticulomesenteric band, diverticulectomy and end to end ileoileal anastomosis. Histopathological examinations revealed diverticular structure lying down with heterotopic small intestinal mucosa with mucosal infarctions.

Although diverticulectomy and dissection of diverticulomesenteric fibrous bands associated with intestinal mesentery or abdominal wall is enough in treatment of symptomatic Meckel's diverticulum; segmental ileal resection may be essential in treatment of complicated cases. There are different opinions on treatment of incidental (asymptomatic) Meckel's diverticulum [7].

In conclusion, awareness of the possibility of that there could be a gangrenous Meckel's diverticulum in a sac of strangulated umblical hernia has the mentionable importance and so, it may creates an innovation in the treatment and the postoperative rehabilitation modalities.

\section{Consent}

The informed written consent was obtained from the patient for publication of this case report and accompanying images. A copy of the written consent is available for review by the Editor-in-Chief of this journal.

\section{Author details}

'Department of General Surgery, Giresun University Faculty of Medicine, 28100 Giresun, Turkey. ${ }^{2}$ Department of Pathology, Prof Dr A Ilhan Ozdemir State Hospital, 28100 Giresun, Turkey. ${ }^{3}$ Department of Radiology, Yuzuncu Yil

University Faculty of Medicine, 65100 Van, Turkey. ${ }^{4}$ Department of General Surgery, Ankara Ataturk Education and Research Hospital, Ankara, Turkey.

Authors' contributions

All authors read and approved the final manuscript.

\section{Competing interests}

The authors declare that they have no competing interests.

Received: 5 November 2009

Accepted: 7 January 2010 Published: 7 January 2010

\section{References}

1. Kremer RM, Morton JH: Strangulated Littre's umbilical hernia. Am Surg 1968, 34(6):432-435.

2. Soderlund S: Meckel's diverticulum. A clinical and histologic study. Acta Chir Scand Suppl 1959, 248:1-233.

3. Yahchouchy EK, Marano AF, Etienne JC, Fingerhut AL: Meckel's diverticulum. J Am Coll Surg 2001, 192(5):658-662.

4. Mackey WC, Dineen P: A fifty year experience with Meckel's diverticulum. Surg Gynecol Obstet 1983, 156(1):: 56-64.

5. St-Vil D, Brandt ML, Panic S, Bensoussan Al, Blanchard H: Meckel's diverticulum in children. A 20-year review. J Pediatr Surg 1991, 26(11):1289-1292.

6. Ford EG, Woolley MM: Tracheoesophageal fistula associated with perforated Meckel's diverticulum. J Pediatr Surg 1992, 27(9):1223-1224.

7. Whang EE, Ashley SW, Zinner MJ: Small intestine. Schwartz's Principles of Surgery U.S.A: The McGraw-Hill CompaniesBrunicardi FC, Andersen DK, Billiar TR, Dunn DL, Hunter JG, Pollock RE , 8 2005, 1017-1054.

8. Owen JK, Finney GG: The surgical aspects of Meckel's diverticulum. South j 1949, 42(2):98-108

9. Rosai J: Gastrointestinal tract. Ackerman's Surgical Pathology London: Mosby CoRosai J , 91949.

10. Williams RS: Management of Meckel's diverticulum. Br J Surg 1981, 68(7):477-480

doi:10.1186/1757-1626-3-10

Cite this article as: Sengul et al:: Gangrenous meckel's diverticulum in a strangulated umbilical hernia in a 42 year-old woman: a case report. Cases Journal 2010 3:10.

Publish with Bio Med Central and every scientist can read your work free of charge

"BioMed Central will be the most significant development for disseminating the results of biomedical research in our lifetime. " Sir Paul Nurse, Cancer Research UK

Your research papers will be:

- available free of charge to the entire biomedical community

- peer reviewed and published immediately upon acceptance

- cited in PubMed and archived on PubMed Central

- yours - you keep the copyright
BioMedcentral 